\title{
II Ein symptomatisches Beispiel für den Reformbedarf: Rückbenennung nach Auflösung der Einbenennungsehe
}

Geradezu symptomatisch für den schlechten Zustand des deutschen Namensrechts steht - um nur ein Beispiel herauszugreifen ${ }^{25}$ - eines der letzten namensrechtlichen Reformvorhaben, das jedoch mit Ablauf der vergangenen Legislaturperiode wegen Diskontinuität gescheitert ist. Die Bundesregierung hatte im Jahr 2016 eine Reform der Einbenennung vorgeschlagen, die in § 1618 BGB geregelt ist. ${ }^{26}$

Das Institut der Einbenennung soll die namensrechtliche Integration eines Stiefkinds in seine soziale Familie ermöglichen, wenn einer der Elternteile mit einem Dritten die Ehe schließt und die Ehegatten einen Ehenamen nach § 1355 BGB bestimmen. In dieser Situation können der Elternteil und der Stiefelternteil dem Kind ihren Ehenamen entweder anstelle seines bisherigen Familiennamens erteilen oder diesem voranstellen oder anfügen, und auf diese Weise ausnahmsweise (siehe näher noch unten IV. 2. b) einen echten Doppelnamen kreieren. ${ }^{27}$ Eine solche Einbenennung setzt voraus, dass das Kind unverheiratet ist, dem erteilenden Elternteil mindestens auch die elterliche Sorge für das Kind zusteht, Elternteil und Stiefelternteil das Kind in ihren gemeinsamen Haushalt aufgenommen haben und - unter bestimmten Voraussetzungen - der andere Elternteil und das Kind in die Einbenennung einwilligen.

Die Bundesregierung wollte in einem neuen $\S 1618$ Abs. 2 BGB die Einbenennung um eine Rückbenennung ergänzen. Das volljährige Kind sollte wieder zu seinem bisherigen Familiennamen zurückkehren können, sich mithin namensrechtlich von der Stieffamilie und vor allem dem namensgebenden Stiefelternteil distanzieren dürfen, wenn die zugrunde liegende Ehe beendet wurde, sei es durch Scheidung, Aufhebung oder Tod.

Auffällig war auf den ersten Blick die tatbestandliche Enge der geplanten Rückbenennungsoption. Warum sollte etwa eine Rückbenennung ausgeschlossen sein, wenn die Ehe vor Erreichen der Volljährigkeit des Kindes endet? Warum sollte überhaupt an die Beendigung der Ehe angeknüpft werden und nicht allein

25 Siehe für eine umfassende Analyse Hepting (Fn. 16) 119 f.; vgl. bereits zuvor Reinhard Hepting Regelungszwecke und Regelungswidersprüche im Namensrecht, StAZ 1996, 1.

26 Entwurf eines Gesetzes zur Reform des Scheinvaterregresses, zur Rückbenennung und zur Änderung des Internationalen Familienrechtsverfahrensgesetzes, BR-Drucks. 493/16.

27 Näher etwa Hepting/Dutta (Fn. 6) Rn. V-852 ff.

Ә OpenAccess. () 2020 Juristische Gesellschaft zu Berlin, publiziert von De Gruyter.

(cc) BY-NC-ND Dieses Werk ist lizenziert unter der Creative Commons Attribution-NonCommercial-NoDerivatives 4.0 License. https://doi.org/10.1515/9783110709872-003 
an den Willen des Stiefkinds, das über seine (namensrechtliche) Verbundenheit zur Stieffamilie am besten entscheiden kann? Als Antwort auf diese Fragen verwies die Begründung des Regierungsentwurfs auf eine weitere Stellschraube des deutschen Namensrechts, die ich bisher übergangen habe: die öffentlichrechtliche Namensänderung nach einem Gesetz, das noch aus dem Jahr 1938 stammt, dem Namensänderungsgesetz ${ }^{28}$ (NamÄndG). Losgelöst vom Namensrecht des Bürgerlichen Gesetzbuchs ermöglicht das Namensänderungsgesetz auf Antrag des Namensträgers eine isolierte - also von personenstandsrelevanten Vorgängen wie Eheschließung oder Geburt unabhängige - Änderung des Namens durch die zuständige Verwaltungsbehörde, „wenn ein wichtiger Grund die Änderung rechtfertigt“ (§ 3 Abs. 1 NamÄndG, gegebenenfalls in Verbindung mit § 11). Zum wichtigen Grund als zentraler Voraussetzung für eine öffentlichrechtliche Namensänderung existiert nicht nur eine umfangreiche Verwaltungsvorschrift. ${ }^{29}$ Auch ist dieses Tatbestandsmerkmal häufig Gegenstand der verwaltungsgerichtlichen (und manchmal sogar familiengerichtlichen ${ }^{30}$ ) Rechtsprechung. Diese öffentlichrechtliche Namensänderung und nicht das neue Rückbenennungsrecht sollte nach Ansicht der Bundesregierung die eben genannten Konstellationen auffangen. ${ }^{31}$ Die vorgeschlagene Neuregelung hätte damit in der Sache lediglich dafür gesorgt, dass bei Aufhebung der Ehe und Volljährigkeit des Namensträgers für die Rückkehr zum bisher geführten Namen kein wichtiger Grund vorliegen muss (und im Übrigen eine etwaige Verwaltungsgebühr für die öffentlichrechtliche Namensänderung entfällt).

28 Gesetz über die Änderung von Familiennamen und Vornamen vom 5.1.1938, RGBl. 1938 I S. 9, das freilich seit seinem Inkrafttreten immer wieder geändert wurde.

29 Allgemeine Verwaltungsvorschrift zum Gesetz über die Änderung von Familiennamen und Vornamen vom 11.8.1980.

30 Siehe etwa zu einem Namensänderungsantrag eines Vormunds zur „Einbenennung“ zweier Pflegekinder BGH 8.1.2020, FamRZ 2020, 585.

31 Begründung des Entwurfs eines Gesetzes u. a. zur Rückbenennung (Fn. 26) S. 19 f. 